\title{
Influence of Er,Cr:YSGG laser on root dentin submitted to erosive and/or abrasive challenges
}

\section{Gabriella Rodovalho PAIVA(a) \\ Regina Guenka Palma DIBB(b) \\ Juliana Jendiroba FARAONI(b) \\ Maria Angélica Hueb de Menezes OLIVEIRA $^{(a)}$ \\ Denise Tornavoi de CASTRO(a) (D) Vinícius Rangel GERALDO-MARTINS(a) Cesar Penazzo LEPRI(a) (iD)}

(a) Universidade de Uberaba - Uniube, School of Dentistry, Department of Biomaterials, Uberaba, MG, Brazil.

(b) Universidade de São Paulo - USP, Ribeirão Preto School of Dentistry, Department of Restorative Dentistry, Ribeirão Preto, SP, Brazil.

Declaration of Interests: The authors certify that they have no commercial or associative interest that represents a conflict of interest in connection with the manuscript.

\section{Corresponding Author:}

Cesar Penazzo Lepri

E-mail: cesarlepri@yahoo.com.br

Submitted: June 5, 2020

Accepted for publication: October 22, 2020

Last revision: November 25, 2020

\begin{abstract}
This study evaluated how Er,Cr:YSGG laser, associated or not with $5 \%$ fluoride varnish, influences the surface roughness and volume loss of bovine root dentin submitted to erosive and/or abrasive wear. One hundred and twenty dentin specimens were divided into the groups: without preventive treatment (WPT), 5\% fluoride varnish (FV); Er,Cr:YSGG laser irradiation (L), and varnish combined with laser (FV $+\mathrm{L})$. The specimens $(\mathrm{n}=10)$ were subdivided into: $1=$ erosion $(\mathrm{E}) ; 2=$ abrasion (A); and $3=$ erosion followed by abrasion $(E+A)$. The erosive solution used was a soft-drink $\left(\mathrm{pH}=2.42\right.$ at $\left.4^{\circ} \mathrm{C}\right)$ applied in 5 -min cycles twice a day for $10 \mathrm{~d}$. Abrasive wear involved brushing for $60 \mathrm{~s}$ with an electric brush (1,600-oscillations/s) at a load of $2.0 \mathrm{~N}$. Surface roughness and volume loss were evaluated using a laser scanning confocal microscope. Roughness data were submitted to one-way ANOVA and Tukey post-hoc test. For volume loss, the Kruskal-Wallis and Dunn's post-hoc tests were used ( $\alpha=5 \%$ ). The lowest values of roughness were found in the control areas of all subgroups $(p>0.05)$. In the experimental area, the $[(\mathrm{WPT})+(\mathrm{E}+\mathrm{A})]$ subgroup had a significantly higher roughness $\left(5.712 \pm 0.163 \mu \mathrm{m}^{2}\right)$ than the other subgroups $(\mathrm{p}<0.05)$. The $\mathrm{L}$ and $(\mathrm{FV}+$ L) groups had statistically similar roughness, regardless of the type of wear. The $(\mathrm{FV}+\mathrm{L})$ group had the lowest volume loss, regardless of the type of wear performed: $[(\mathrm{FV}+\mathrm{L})+(\mathrm{E})]=7.5 \%,[(\mathrm{FV}+\mathrm{L})+(\mathrm{A})=7.3 \%$, and $[(\mathrm{FV}+\mathrm{L})+(\mathrm{E}+\mathrm{A})]=8.1 \%$. The subgroup $[(\mathrm{WPT})+(\mathrm{E}+\mathrm{A})]$ had the highest volume loss (52.3\%). The proposed treatments were effective in controlling dentin roughness. Laser irradiation can be an effective method to increase root dentin resistance after challenges and limit problems related to non-carious lesions.
\end{abstract}

Keywords: Tooth Erosion; Fluorides; Tooth Abrasion; Laser, Solid-State.

\section{Introduction}

The increase in life expectancy and the improvement in preventive techniques offered in the field of dentistry have contributed to a greater longevity and maintenance of natural teeth in the oral cavity. ${ }^{1}$ However, the number of non-carious cervical lesions (NCCLs) has gradually increased due to behavioral changes of the population. ${ }^{2,3}$

These lesions arise due to an irreversible loss of enamel and dentin at the cement-enamel junction without bacterial involvement. ${ }^{4}$ With 
a multifactorial etiology, NCCLs associated with dental erosion, abrasion, abfraction, and attrition cause the root surface to be exposed. ${ }^{5}$ In addition, the combination of potential etiological factors for NCCL development, such as dental erosion and dental abrasion processes, ${ }^{6}$ can cause cervical dentin hypersensitivity and an accumulation of biofilm in the region.?

Dental erosion is caused by endogenous or exogenous acids. ${ }^{89}$ The consumption of citrus fruits and juices, soft drinks, alcoholic drinks, vitamin $\mathrm{C}$ tablets, and isotonic drinks, because of their low $\mathrm{pH}$ and high erosive potential, are recognized in the literature as a source of injury to the dental structure, characterized by extrinsic dental erosion. ${ }^{3,8,10}$ Additionally, intrinsic factors include changes in $\mathrm{pH}$ due to hydrochloric acid from the stomach reaching the oral cavity through vomiting, regurgitation, or gastroesophageal reflux, from disorders such as bulimia, anorexia, or hiatal hernia. ${ }^{3}$

The influence of abrasion from toothbrushing on the progression of NCCLs is controversial. According to Shellis and Addy, ${ }_{11}^{11}$ under normal and adequate conditions, toothbrushing using commercials toothpaste causes minimal dentin wear throughout life. However, depending on the force applied during brushing dental wear, dental weat could aggravate. ${ }^{4,5}$

Preventive treatments for dental erosion are directed against causal factors and may include changes to the diet and a reduced consumption of acidic drinks because it is well known that the patient's habits play a major impact on preventing erosion/abrasion. ${ }^{8}$ Modifications of the tooth surface can also increase the resistance to acidic challenges, for which fluorides have been effective. ${ }^{8,12}$ Fluoridecontaining solutions promote a protective effect, which has been demonstrated in in vitro and in situ studies. ${ }^{8,13}$ The topical application of fluoride agents, such as sodium fluoride $(\mathrm{NaF})$, can protect against dental erosion through the formation of $\mathrm{a} \mathrm{CaF}_{2}$ layer on the surface. ${ }^{14}$

Irradiation with the Er,Cr:YSGG laser on the dental surface causes an increase in the surface temperature and alters its chemical structure, making the surface less soluble. ${ }^{15}$ A previous study has investigated the effectiveness of Er:YAG laser irradiation, with or without a fluoride agent, against abrasive wear on tooth enamel. ${ }^{16}$ The results showed that the proposed treatment was effective only when associated with the fluoride agent, since it promoted morphological changes in the enamel structure, which provided greater $\mathrm{CaF}_{2}$ retention and helped to control abrasive wear. The behavior was expected to be similar with dentin. Additionally, when the enamel and dentin are irradiated with a laser, the surfaces are partially melted and solidified, which suggests that these surfaces would be less permeable. ${ }^{16}$ According to He et al., ${ }^{17}$ Er:YAG laser irradiation affected both mineral and organic components in the subsurface dentin layer, leading to a higher degree of crystallinity and reduced organic compounds.

As mentioned above, the effect of erbium lasers in dentin submitted to erosive or abrasive processes has been studied. The present study differs from the others because it also compared the combination of erosion followed by abrasion. Dentin substrate was used instead of enamel so that the results could be extrapolated to clinical conditions of dentin hypersensitivity. ${ }^{7}$

Therefore, the aim of this in vitro study was to evaluate the influence of the Er,Cr:YSGG laser associated or not with 5\% fluoride varnish on the surface roughness and volume loss of bovine root dentin subjected to erosive and/or abrasive wear, measured using confocal laser scanning microscopy. The hypothesis of the present study was that the erosive and/or abrasive challenges and the different preventive treatments would result in statistically significant differences in surface roughness and loss of volume in bovine root dentin.

\section{Methodology}

\section{Experimental design}

The factors under study were the preventive treatment methods (5\% fluoride varnish, Er,Cr:YSGG laser irradiation, and varnish combined with laser) and the challenges (erosion, abrasion, and erosion followed by abrasion). The quantitative response variables were surface roughness (in $\mu \mathrm{m}^{2}$ ) and loss of volume (in \%). Figure 1 shows the study flowchart. 
120 Root Dentin Specimens

Preventive Treatments

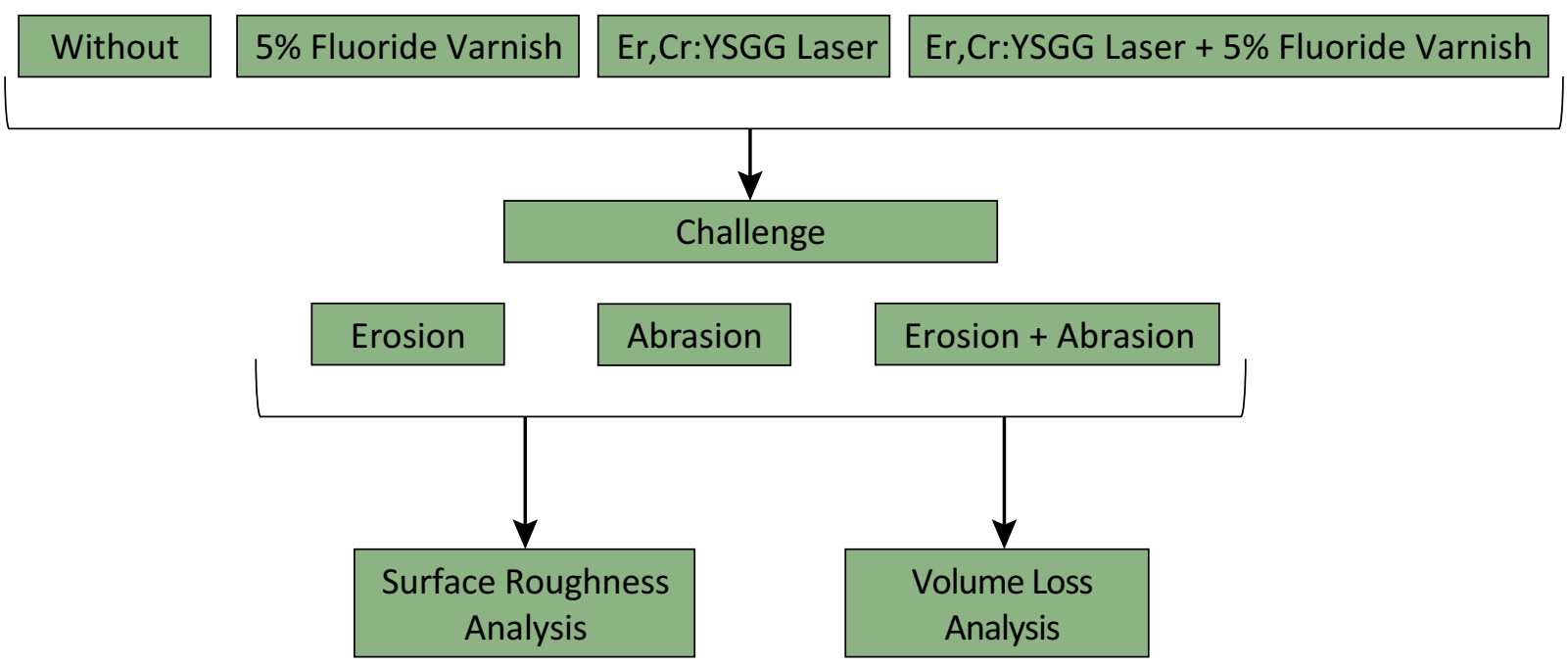

Figure 1. Flowchart of the study.

\section{Teeth selection and samples preparation}

After approval by the Animal Experimentation Ethics Committee of the University of Uberaba under protocol number $028 / 2018,60$ bovine incisors without any cracks or wear were selected. The teeth were cleaned and then immersed in a $10 \%$ formalin solution for disinfection $(\mathrm{pH}=7)$ for 7 days. Afterwards, the teeth were washed and stored in distilled and deionized water at a temperature of $4^{\circ} \mathrm{C}$, which was changed daily for a period of 14 days. ${ }^{8}$

The coronary portion of the root was sectioned using a diamond disk under refrigeration in the ISOMET $1000^{\circledR}$ cutting machine (Precision Saw Buehler, Lake Bluff, USA). The first cut was made $1 \mathrm{~mm}$ below the cementoenamel junction. The second cut was made in the buccal-lingual direction, resulting in two halves (mesial and distal). Each half was again sectioned to obtain specimens with the dimensions of $4.25 \mathrm{~mm} x$ $4.25 \mathrm{~mm} \times 2.5 \mathrm{~mm}$. The sides of the specimens were sanded with an Arotec APL-4 polishing machine (Series 41042, Arotec S.A. Industry and Commerce, Cotia, Brazil) using a \#600 sandpaper under water cooling, resulting in a surface area of $18 \mathrm{~mm}^{2}$. The external (buccal) surface of the specimen was not polished. A $10 \%$ positive or negative variation in dimensions was allowed. Half of the surface of each specimen was covered with electrical tape. Two layers of red nail polish (Risqué Maybelline Ltda, Sao Paulo, Brazil) and sculpting wax (Kota Industria, Cotia, Brazil) were applied, isolating the area. After this procedure, the tape was removed, and each specimen had a control surface coated with nail polish and wax protection. The specimens were stored in distilled and deionized water at a temperature of $4^{\circ} \mathrm{C}$ until the proposed treatment was performed ${ }^{8,18}$ at which point they were randomly divided into 12 subgroups $(n=10)$, according to the preventive treatments. The sample size was calculated by setting the level of significance at $5 \%$ and the test power at $90 \%$.

\section{Preventive treatment of specimens}

The fluoride varnish ( $5 \%$ sodium fluoride) used was Duraphat $^{\circledR}$ - 22600 ppm fluoride (Colgate Palmolive Ind. e Com. Ltda, Sao Paulo, Brazil). A disposable applicator (KG Brush, KG Sorensen, Cotia, Brazil) was used to apply the varnish on the buccal face 
of the previously waterproofed specimens. After 4 minutes, the excess was removed with a sterile gauze. A Er,Cr:YSGG laser (Waterlase Millennium, Biolase Technologies Inc., San Clemente, USA) was used with $600 \mu \mathrm{m}$ diameter fiber (tip model: ZipTip MZ6 $3 \mathrm{~mm}$ ), at a wavelength of $2.78 \mu \mathrm{m}$, with $10 \mathrm{~s}$ of irradiation in the scanning mode $1 \mathrm{~mm}$ away from the target tissue, at $0.5 \mathrm{~W}$ power, a repetition rate of $5.0 \mathrm{~Hz}$, and an energy density of $6.25 \mathrm{~J} / \mathrm{cm}^{2} .{ }^{8}$ To simulate a clinical condition, a calibrated operator manually scanned the dentin surface (approximately $8.0 \mathrm{~mm} / \mathrm{s})$ with the laser light for a period of $10 \mathrm{~s}(5 \mathrm{~s}$ horizontally and $5 \mathrm{~s}$ vertically). The use of the laser without water cooling was based on a previous study, ${ }^{13}$ where it was shown that the water could cause ablation in the tissue, making it less effective as a preventive treatment.

\section{Erosive challenge}

After the treatments, the specimens were submitted to an erosive challenge using a carbonated soft drink (Coca-Cola ${ }^{\circledR}$, Uberlandia Refrescos LTDA, Uberlandia, Brazil) with a $\mathrm{pH}$ of 2.43 at $4^{\circ} \mathrm{C}$, according to Arantes et al. ${ }^{8}$ and modified for the present study. Each subgroup was placed separately in a beaker with $50 \mathrm{~mL}$ of the drink for $5 \mathrm{~min}$, with a magnetic stirrer (model 221-1, ABC-LAB Produtos e Equipamentos Laboratorios, Sao Bernardo do Campo, Brazil). The erosive solution was then discarded, the specimens were washed with distilled and deionized water for 10s, stored in artificial saliva, and placed in an oven at $37^{\circ} \mathrm{C}$ between cycles. This procedure was performed twice a day, with a $2 \mathrm{~h}$ interval between challenges, for a period of $10 \mathrm{~d}$. The artificial saliva had the following chemical composition: $\mathrm{KH}_{2} \mathrm{PO}_{4}$, $\mathrm{K}_{2} \mathrm{HPO}_{4}, \mathrm{KCl}, \mathrm{NaCl}, \mathrm{MgCl}_{2} \cdot 6 \mathrm{H}_{2} \mathrm{O}, \mathrm{CaCl}_{2} \cdot 2 \mathrm{H}_{2} \mathrm{O}$, sorbitol, nipagin, nipasol, carboxymethylcellulose (CMC), and water; $\mathrm{pH}=7.00$ at $37^{\circ} \mathrm{C}$.

\section{Abrasive challenge}

Abrasive wear was performed by brushing the buccal surface of the specimens 1 hour after the second daily erosive challenge ${ }^{19}$ by the same operator. The specimens were brushed in vitro with soft-bristle electric toothbrushes with rounded tips (Oral-B Professional Care 5000, Procter and Gamble, Marktheidenfeld,
Germany), which simulated an oscillatory brushing technique parallel to the central mark limiting the area subjected to the cycles. The dentifrice used was Colgate Total 12 Clean Mint (Colgate-Palmolive Industrial Ltda, São Paulo, Brazil). A solution (slurry) was prepared $20 \mathrm{~min}$ before use by mixing the toothpaste and distilled water at a proportion of 1:2 by weight. The brush head (Precision Clean, Procter and Gamble, São Paulo, Brazil) had three sets of soft bristles with different shapes positioned at different angles and heights. The electric toothbrush was attached to a device and a force of $2.0 \mathrm{~N}(\approx 200 \mathrm{~g})$ was applied during brushing for $1 \mathrm{~min}$ (166 oscillations/s). The slurry solution was injected between the bristles at the beginning and at every $15 \mathrm{~s}$, and the specimens remained in contact with the slurry for 2 min after brushing. ${ }^{18}$ Considering the average brushing time of approximately 20s per face, the present study used the total time of $1 \mathrm{~min}$ to simulate three daily brushings. ${ }^{20}$ Afterwards, the specimens were washed with distilled and deionized water for 10s, lightly dried with absorbent paper, and then kept in $25 \mathrm{~mL}$ of artificial saliva and stored at $37^{\circ} \mathrm{C}$.

\section{Analysis of the surface roughness and volume loss}

After treatment followed by erosive and/or abrasive challenges, the specimens were analyzed using a laser scanning confocal microscope. The specimens were immersed in distilled and deionized water, inserted in an ultrasonic vat (Ultrasonic Cleaner 740D - Odontobras - Ribeirao Preto, Brazil), stirred for $5 \mathrm{~min}$, and later positioned parallel to the table of the LEXT laser-scanning microscope (Olympus, Tokyo, Japan) with the aid of a parallelometer.

These analyses were performed by the same highly trained and experienced operator (specialist technician), who was blinded and calibrated. The calibration was done by the initial validation of the OLS4000 ${ }^{\circledR}$ software, and for blinding, the experimental specimens were coded before the analyses and the operator did not participate in the other methodological steps.

After selecting the central region of the $1 \mathrm{~mm} x$ $1 \mathrm{~mm}$ specimen, images were acquired using a 10x magnification lens and analyzed for surface roughness (Ra parameter in $\mu \mathrm{m}^{2}$ ) and volume loss (\%), and the 
control and experimental regions were compared. The data were acquired using a specific software (OLS4000 ${ }^{\circledR}$ - Olympus, Japan).

The difference in the volume of the control and experimental regions of each specimen was determined, taking into account the midline of the graph. The data were obtained in $\mu \mathrm{m}^{3}$ and, for statistical calculations, transformed into percentage of lost volume.

\section{Statistical analysis}

The data were analyzed for distribution (Kolmogorov-Smirnov) and homogeneity (Levene). As these conditions were met, the surface roughness data were subjected to one-way ANOVA and to Tukey's post-hoc for multiple comparisons. To analyze volume loss, the data were subjected to the Kruskal-Wallis test and the Dunn post-hoc test. All statistical tests adopted a significance level of $5 \%(\alpha=0.05)$.

\section{Results}

\section{Surface roughness}

The surface roughness values are described in Table $(\mathrm{n}=10)$. In the control areas, all subgroups showed lower values of surface roughness that were statistically similar to each other ( $p>0.05)$, and statistically different from the experimental areas $(\mathrm{p}<0.05)$.

For the experimental areas, the surface roughness in the negative control subgroup [(WPT) $+(\mathrm{E}+\mathrm{A})]$ was the highest $\left(5.712 \pm 0.163 \mu \mathrm{m}^{2}\right)$, with a statistically significant difference from the other subgroups $(p<0.05)$. There was no statistically significant difference between the $\mathrm{L}$ and $(\mathrm{FV}+\mathrm{L})$ subgroups, regardless of the type of wear $(p>0.05)$. Among the proposed treatments, the $[(\mathrm{FV}+(\mathrm{E}+\mathrm{A})]$ subgroup had a surface roughness of $3.355 \pm 0.098 \mu \mathrm{m}^{2}$, which was significantly different from the other FV treatment groups $(\mathrm{p}<0.05)$.

\section{Percentage of volume loss}

As described in Table, $(\mathrm{FV}+\mathrm{L})$ showed the lowest volume loss $(\mathrm{p}<0.05)$ regardless of the wear performed: $[(\mathrm{FV}+\mathrm{L})+(\mathrm{E})]=7.5 \%,[(\mathrm{FV}+\mathrm{L})+(\mathrm{A})]=$ $7.3 \%$, and $[(\mathrm{FV}+\mathrm{L})+(\mathrm{E}+\mathrm{A})]=8.1 \%$. However, the greatest volume loss was observed in the $[(\mathrm{WPT})+$ $(E+A)]$ subgroup, at $57.2 \%$. Microscopically, there were great differences in the coloration between the control and experimental regions (Figure 2).

Table. Mean values and standard deviation of the surface roughness $\left(\mu \mathrm{m}^{2}\right)$ and volume loss (\%) of the groups, considering the control and experimental regions.

\begin{tabular}{|c|c|c|c|c|c|}
\hline Preventive treatment & Type of challenge & Subgroup code & $\begin{array}{l}\text { Roughness in control } \\
\text { region }\end{array}$ & $\begin{array}{l}\text { Roughness in } \\
\text { experimental region }\end{array}$ & Volume loss \\
\hline \multirow{3}{*}{$\begin{array}{l}\text { Without Preventive } \\
\text { Treatment (WPT) }\end{array}$} & 1.Erosion & {$[(\mathrm{WPT})+(\mathrm{E})]$} & $0.812(0.061)^{a}$ & $3.592(0.092)^{c}$ & $37.8(2.9)^{\mathrm{D}}$ \\
\hline & 2.Abrasion & {$[(\mathrm{WPT})+(\mathrm{A})]$} & $0.867(0.084)^{a}$ & $3.734(0.075)^{c}$ & $35.1(3.5)^{\mathrm{D}}$ \\
\hline & 3.Erosion + Abrasion & {$[(\mathrm{WPT})+(\mathrm{E}+\mathrm{A})]$} & $0.845(0.077)^{a}$ & $5.712(0.163)^{d}$ & $57.2(4.1)^{\mathrm{E}}$ \\
\hline \multirow{3}{*}{ 5\% Fluoride Varnish (FV) } & 1.Erosion & {$[(F V)+(E)]$} & $0.844(0.069)^{a}$ & $2.132(0.084)^{b}$ & $23.9(2.4)^{\mathrm{C}}$ \\
\hline & 2.Abrasion & {$[(\mathrm{FV})+(\mathrm{A})]$} & $0.832(0.057)^{a}$ & $2.251(0.090)^{\mathrm{b}}$ & $34.7(3.0)^{\mathrm{D}}$ \\
\hline & 3.Erosion+ Abrasion & {$[(F V)+(E+A)]$} & $0.872(0.080)^{a}$ & $3.355(0.098)^{c}$ & $36.7(3.9)^{\mathrm{D}}$ \\
\hline \multirow{3}{*}{ Er,Cr:YSGG Laser (L) } & 1.Erosion & {$[(L)+(E)]$} & $0.846(0.056)^{a}$ & $2.101(0.059)^{b}$ & $13.4(2.6)^{\mathrm{B}}$ \\
\hline & 2.Abrasion & {$[(L)+(A)]$} & $0.837(0.081)^{a}$ & $2.136(0.080)^{b}$ & $14.0(3.1)^{\mathrm{B}}$ \\
\hline & 3.Erosion + Abrasion & {$[(L)+(E+A)]$} & $0.866(0.085)^{a}$ & $2.205(0.084)^{b}$ & $14.4(2.3)^{\mathrm{B}}$ \\
\hline \multirow{3}{*}{ Varnish + Laser (FV+L) } & 1.Erosion & {$[(F V+L)+(E)]$} & $0.841(0.074)^{a}$ & $2.015(0.087)^{b}$ & $7.5(1.2)^{\mathrm{A}}$ \\
\hline & 2.Abrasion & {$[(F V+L)+(A)]$} & $0.840(0.053)^{a}$ & $2.041(0.095)^{b}$ & $7.3(1.5)^{\mathrm{A}}$ \\
\hline & 3.Erosion + Abrasion & {$[(F V+L)+(E+A)]$} & $0.849(0.083)^{a}$ & $2.263(0.086)^{b}$ & $8.1(1.7)^{\mathrm{A}}$ \\
\hline
\end{tabular}

*Equal letters represent statistical similarity between subgroups $(p>0.05)$; small letters for roughness and capital letters for volume loss 


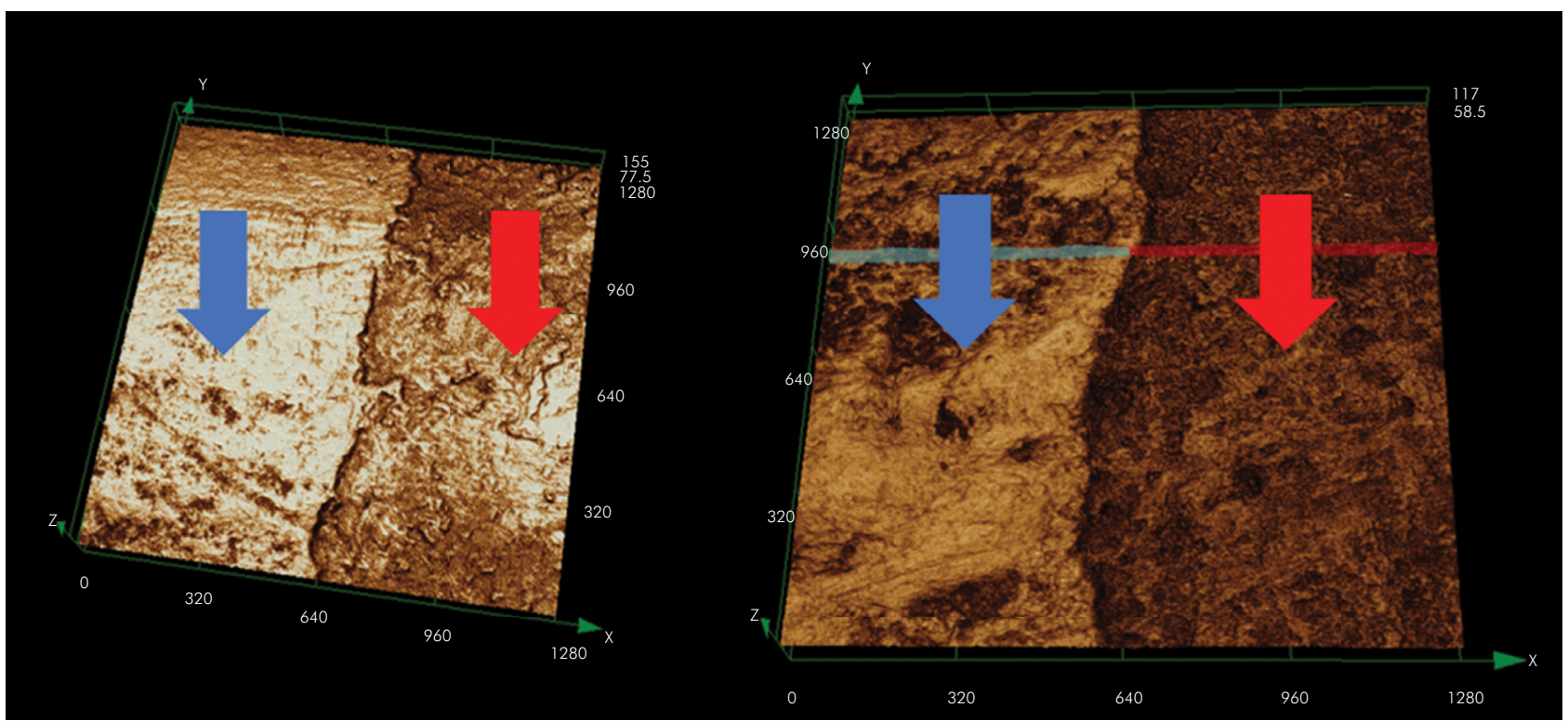

Figure 2. Representative images of specimens obtained by confocal laser scanning ( $\times 20$ magnification). The blue arrow indicates the control region (root dentin without exposure to preventive treatments and challenges) and the red arrow indicates the experimental region (exposed to preventive treatments and challenges).

\section{Discussion}

Erosion and abrasion are important mechanisms of dental wear. Among the numerous existing methods for assessing the superficial morphology of hard dental tissues, confocal laser scanning microscopy provides high resolution images and allows better surface characterization, such as enamel prisms, dentinal tubules, and demineralization areas ${ }^{18}$ since it does not generate damage to the specimen surface, unlike scanning electron microscopy. ${ }^{21}$ In the present study, the control and experimental regions showed significant differences in surface roughness and volume loss $(\mathrm{p}<0.05)$. Therefore, the research hypothesis that exposure to erosive and/or abrasive challenges and different treatments would result in statistically significant differences was confirmed.

NCCLs are highly prevalent in the population.,22 According to some authors, their etiology is multifactorial, meaning they begin and progress due to the interaction of different wear processes, ${ }^{5,23}$ including erosion (corrosive wear), abrasion (abrasive wear), friction (occlusal overload, usually associated with abrasion), and attrition. In advanced stages, NCCLs compromise the function and aesthetics of the teeth involved, and dentin hypersensitivity may appear, which often requires extensive restorative treatment. ${ }^{24}$

For this study, the immersion of the specimens in a cola-based soft-drink was chosen due to its great erosive potential, widely discussed in the scientific literature, ${ }^{8,10,12}$ in addition to being a drink consumed worldwide. Its $\mathrm{pH}$ is around 2.43 at the usual drinking temperature, which is below the critical dentin dissolution $\mathrm{pH}(<6.5)$, promoting demineralization of the dentin surface. ${ }^{8,11}$ This corroborates the current study results, which showed the superficial demineralization of dentin after exposure to Coca-Cola ${ }^{\circledast}$. It is speculated that erosive events release the collagen matrix from dentin, during hydroxyapatite dissolution, which could provide a temporary protective role for this tissue. According to Shellis et al.,r ${ }^{25}$ the collagen layer is largely unaffected by dietary erosion and forms a mat of fibrils as the mineralized matrix dissolves, although abrasive influences will probably result in surface change. The relevance and clinical implications of this layer in the erosion/abrasion wear of dentin have yet to be fully understood.

The data obtained demonstrated an increase in dentin roughness, and the presence of irregularities 
causes a greater accumulation of biofilm, increasing the chances of developing carious lesions and periodontal problems. ${ }^{19,26}$

The subgroup $[(\mathrm{WPT})+(\mathrm{E}+\mathrm{A})]$ showed the highest surface roughness $\left(5.712 \mu \mathrm{m}^{2}\right)$ and volume loss $(57.2 \%)$, demonstrating the potential for dentin wear by two combined challenges, erosion followed by abrasion, which reinforces the need for preventive measures.

$\mathrm{NaF}$ can provide protection to dental enamel by releasing calcium ions into oral fluids in acidic conditions, which can increase the concentration of calcium in saliva. ${ }^{27}$ The degree of saturation of enamel hydroxyapatite can thus change, contributing to the inhibition of demineralization and an increase in remineralization. ${ }^{10,15,28}$ Considering that hydroxyapatite is one of the main constituents of enamel and dentin, it is expected that fluoride protects dentin against the demineralization process through a similar mechanism. ${ }^{8}$ Kim et al. ${ }^{29}$ demonstrated that during the demineralization and remineralization processes, fluoride agents promote the formation of fluoroapatite or fluoride hydroxyapatite, which are more resistant to dissolution in an acidic medium. Furthermore, the use of fluoride varnish has been recommended, as the technique increases the contact time of the exposed dentin to the fluoride, thus increasing effectiveness. ${ }^{8}$

In the present study, the FV group with the highest surface roughness was the $[(\mathrm{FV})+(\mathrm{E}+\mathrm{A})]$ subgroup, which was significantly different from the other FV-treated specimens. However, it presented a lower volume loss from erosion than the other types of wear. This can be explained by the fact that fluoride, even in the form of varnish, is easily removed with brushing or in an acidic medium. ${ }^{30}$

According to a previous study, dentin wear is related to toothpaste abrasiveness, measured using Relative Dentine Abrasivity (RDA). The International Organization for Standardization (ISO \# 11609) recommends that dentifrices should have an RDA of less than $250 .{ }^{11}$

It is important to note that the daily-use toothpaste used in the present study has $1450 \mathrm{ppm}$ of fluoride and silica as an abrasive agent $(\mathrm{RDA}=139.1 \pm 4.51)$, which may have removed the fluoride varnish. This can be seen by comparing the volume loss of the subgroups $[(\mathrm{FV})+(\mathrm{A})]=34.7 \%$ and $[(\mathrm{WPT})+(\mathrm{A})]$ $=35.1 \%$, which were statistically similar $(\mathrm{p}>0.05)$, corroborating the findings of another study ${ }^{31}$ that evaluated the same toothpaste, showing it had higher RDA than Sensodyne Protection and Repair (102.6 $\pm 3.24)$ and Colgate Sensitive Pro-Relief $(81 \pm 3.55)$.

Therefore, it is suggested that preventive treatment with a single application of a fluoride agent seems to have influenced the surface roughness of dentin submitted to erosion and abrasion, likely promoting the formation of a $\mathrm{CaF}_{2}$ layer, ${ }_{1}^{14}$ which may have been removed by toothbrushing. The abrasiveness of the toothpaste and the low $\mathrm{pH}$ of the beverage used can negatively influence surface roughness, especially since these events are associated in the oral cavity.

The specimens were brushed with oscillatingrotating brush head with three sets of soft bristles of different shapes positioned at different angles. ${ }^{32}$ Dentin wear occurred due to the high number of brushing movements produced by the electric method and the application of $2 \mathrm{~N}$ of force. The action of the bristles of electric toothbrushes associated with the high abrasiveness of the toothpaste promotes greater dentin wear than regular toothbrushes. ${ }^{33,34,35}$

In previous studies, $\mathrm{NaF}$ has been shown to have excellent results in reducing the progression of enamel erosion and protecting the precipitation of calcium fluoride on eroded dental surfaces, especially when used in high concentrations. ${ }^{3,36,37}$ In the present study, fluoride varnish proved to be more effective in preventing erosion than the WT group. However, for situations of abrasion or $(E+A)$, it did not have the same protective effect.

For volume loss, there was no significant difference between the groups irradiated with $L(p>0.05)$. The $(\mathrm{FV}+\mathrm{L})$ group presented the lowest volume loss, regardless of the type of wear performed. The combination of laser and fluorides has been shown to potentiate the effect of each method individually, improving the incorporation of fluoride ions into the root dentin and increasing its resistance to acid. 8,13,38 Even when applied isolated, the Er,Cr:YSGG laser presents the advantage of obliterating dentinal tubules after the fusion and rehardening mechanisms, differently from other light sources. ${ }^{39}$ 
The Er,Cr:YSGG laser has also been used clinically, showing satisfactory results in the control of dentin hypersensitivity. ${ }^{40}$ In vitro studies showed that Er,Cr:YSGG laser has a great interaction with dentin due to its high absorption coefficient in both water and hydroxyapatite, altering the structural composition and decreasing solubility. ${ }^{8,18}$ Accordingly, researchers are now encouraged to apply the laboratory results in new clinical research, aiming to establish clinical protocols for increasing the acid resistance of dentin.

The dental surgeon has a fundamental role in informing patients about the importance of a less acidic diet and the use of soft-bristle toothbrushes and less abrasive toothpaste to prevent the onset and progression of NCCLs.

Future studies should analyze other physicalmechanical properties, such as the color stability of the dental substrate, the longitudinal microhardness, and the bond strength of the substrate to restorative materials in order to investigate the longevity of restorative techniques used in irradiated dentin.

\section{Conclusion}

Considering the results obtained and the limitations of this in vitro study, the proposed treatments were effective in controlling surface roughness of root dentin. Laser irradiation, especially when associated to previous fluoride application, resulted in less loss of dental tissue, and it can be an effective preventive method to limit problems related to non-carious lesions.

\section{Acknowledgments}

The authors would like to thank the financial support (scholarship) of the following funding agencies: Capes (PROSUP-BOLSA), CNPq (PIBIC), FAPEMIG (PIBIC), and PAPE-UNIUBE.

We would like to thank Editage ${ }^{\circledR}$ for the initial English language editing and Katia Muller for the final Scientific Language Review.

This study was financed in part by the Coordenação de Aperfeiçoamento de Pessoal de Nível Superior Brasil (CAPES) - Finance Code 001.

\section{References}

1. Hellyer PH. The older dental patient - who cares? Br Dent J. 2011 Aug;211(3):109-11. https://doi.org/10.1038/sj.bdj.2011.618

2. Yang J, Cai D, Wang F, He D, Ma L, Jin Y, et al. Non-carious cervical lesions (NCCLs) in a random sampling community population and the association of NCCLs with occlusive wear. J Oral Rehabil. 2016 Dec;43(12):960-6. https://doi.org/10.1111/joor.12445

3. Carvalho TS, Colon P, Ganss C, Huysmans MC, Lussi A, Schlueter N, et al. Consensus Report of the European Federation of Conservative Dentistry: erosive tooth wear - diagnosis and management. Swiss Dent J. 2016;126(4):342-6.

4. Brandini DA, de Sousa AL, Trevisan Cl, Pinelli LA, do Couto Santos SC, Pedrini D, et al. Noncarious cervical lesions and their association with toothbrushing practices: in vivo evaluation. Oper Dent. 2011 Nov-Dec;36(6):581-9. https://doi.org/10.2341/10-152-S

5. Grippo JO, Simring M, Coleman TA. Abfraction, abrasion, biocorrosion, and the enigma of noncarious cervical lesions: a 20-year perspective. J Esthet Restor Dent. 2012 Feb;24(1):10-23. https://doi.org/10.1111/j.1708-8240.2011.00487.x

6. Schlveter N, Amaechi BT, Bartlett D, Buzalaf MA, Carvalho TS, Ganss C, et al. Terminology of Erosive Tooth Wear: Consensus Report of a Workshop Organized by the ORCA and the Cariology Research Group of the IADR. Caries Res. 2020;54(1):2-6. https://doi.org/10.1159/000503308

7. Teixeira DN, Zeola LF, Machado AC, Gomes RR, Souza PG, Mendes DC, et al. Relationship between noncarious cervical lesions, cervical dentin hypersensitivity, gingival recession, and associated risk factors: A cross-sectional study. J Dent. 2018 Sep;76:93-7. https://doi.org/10.1016/i.jdent.2018.06.017

8. Arantes BF, Mendonça LO, Palma-Dibb RG, Faraoni JJ, Castro DT, Geraldo-Martins VR, et al. Influence of Er,Cr:YSGG laser, associated or not to desensitizing agents, in the prevention of acid erosion in bovine root dentin. Lasers Med Sci. 2019 Jul;34(5):893900. https://doi.org/10.1007/s10103-018-2669-4

9. Hermont AP, Oliveira PA, Martins CC, Paiva SM, Pordeus IA, Auad SM. Tooth erosion and eating disorders: a systematic review and meta-analysis. PLoS One. 2014 Nov;9(11):e111123. https://doi.org/10.1371/journal.pone.0111123

10. Lussi A, Megert B, Shellis RP, Wang X. Analysis of the erosive effect of different dietary substances and medications. Br J Nutr. 2012 Jan;107(2):252-62. https://doi.org/10.1017/S0007114511002820

11. Shellis RP, Addy M. The interactions between attrition, abrasion and erosion in tooth wear. Monogr Oral Sci. 2014;25:32-45. https://doi.org/10.1159/000359936 
12. Alexandria AK, Vieira TI, Pithon MM, da Silva Fidalgo TK, Fonseca-Gonçalves A, Valença AM, et al. In vitro enamel erosion and abrasion-inhibiting effect of different fluoride varnishes. Arch Oral Biol. 2017 May;77:39-43. https://doi.org/10.1016/j.archoralbio.2017.01.010

13. Geraldo-Martins VR, Lepri CP, Faraoni-Romano JJ, Palma-Dibb RG. The combined use of Er,Cr:YSGG laser and fluoride to prevent root dentin demineralization. J Appl Oral Sci. 2014 Sep-Oct;22(5):459-64. https://doi.org/10.1590/1678-775720130570

14. Magalhães AC, Wiegand A, Rios D, Buzalaf MA, Lussi A. Fluoride in dental erosion. Monogr Oral Sci. 2011;22:158-70. https://doi.org/10.1159/000325167

15. Freitas PM, Rapozo-Hilo M, Eduardo CP, Featherstone JD. In vitro evaluation of erbium, chromium:yttrium-scandium-gallium-garnet laser-treated enamel demineralization. Lasers Med Sci. 2010 Mar;25(2):165-70. https://doi.org/10.1007/s10103-008-0597-4

16. Scatolin RS, Colucci V, Lepri TP, Alexandria AK, Maia LC, Galo R, et al. Non-contact profilometry of eroded and abraded enamel irradiated with an Er:YAG laser. J Appl Oral Sci. 2018;26(0):e20170029. https://doi.org/10.1590/1678-7757-2017-0029

17. He Z, Chen L, Hu X, Shimada Y, Otsuki M, Tagami J, et al. Mechanical properties and molecular structure analysis of subsurface dentin after Er:YAG laser irradiation. J Mech Behav Biomed Mater. 2017 Oct;74:274-82. https://doi.org/10.1016/i.jmbbm.2017.05.036

18. Resende RF, Arantes BF, Palma-Dibb RG, Faraoni JJ, de Castro DT, de Menezes Oliveira MA, et al. Influence of Er, Cr:YSGG laser on dentin acid resistance after erosive challenge. Am J Dent. 2019 Oct;32(5):215-8.

19. Lepri CP, Palma-Dibb RG. Surface roughness and color change of a composite: influence of beverages and brushing. Dent Mater J. 2012;31(4):689-96. https://doi.org/10.4012/dmi.2012-063

20. De Menezes M, Turssi CP, Hara AT, Messias DC, Serra MC. Abrasion of eroded root dentine brushed with different toothpastes. Clin Oral Investig. 2004 Sep;8(3):151-5. https://doi.org/10.1007/s00784-004-0262-7

21. dos Reis Derceli J, Faraoni-Romano JJ, Azevedo DT, Wang L, Bataglion C, Palma-Dibb RG. Effect of pretreatment with an Er:YAG laser and fluoride on the prevention of dental enamel erosion. Lasers Med Sci. 2015 Feb;30(2):857-62. https://doi.org/10.1007/s10103-013-1463-6

22. Yoshizaki KT, Francisconi-Dos-Rios LF, Sobral MA, Aranha AC, Mendes FM, Scaramucci T. Clinical features and factors associated with non-carious cervical lesions and dentin hypersensitivity. J Oral Rehabil. 2017 Feb;44(2):112-8. https://doi.org/10.1111/joor.12469

23. Que K, Guo B, Jia Z, Chen Z, Yang J, Gao P. A cross-sectional study: non-carious cervical lesions, cervical dentine hypersensitivity and related risk factors. J Oral Rehabil. 2013 Jan;40(1):24-32. https://doi.org/10.1111/j.1365-2842.2012.02342.x

24. Sabrah AH, Turssi CP, Lippert F, Eckert GJ, Kelly AB, Hara AT. 3D-Image analysis of the impact of toothpaste abrasivity on the progression of simulated non-carious cervical lesions. J Dent. 2018 Jun;73:14-8. https://doi.org/10.1016/i.jdent.2018.03.012

25. Shellis RP, Barbour ME, Jones SB, Addy M. Effects of $\mathrm{pH}$ and acid concentration on erosive dissolution of enamel, dentine, and compressed hydroxyapatite. Eur J Oral Sci. 2010 Oct;118(5):475-82. https://doi.org/10.1111/j.1600-0722.2010.00763.x

26. Nogueira RD, Silva CB, Lepri CP, Palma-Dibb RG, Geraldo-Martins VR. Evaluation of Surface Roughness and Bacterial Adhesion on Tooth Enamel Irradiated With High Intensity Lasers. Braz Dent J. 2017 Jan-Feb;28(1):24-9. https://doi.org/10.1590/0103-6440201701190

27. Baumann T, Bereiter R, Lussi A, Carvalho TS. The effect of different salivary calcium concentrations on the erosion protection conferred by the salivary pellicle. Sci Rep. 2017 Oct;7(1):12999. https://doi.org/10.1038/s41598-017-13367-3

28. Gao XL, Pan JS, Hsu CY. Laser-fluoride effect on root demineralization. J Dent Res. 2006 Oct;85(10):919-23. https://doi.org/10.1177/154405910608501009

29. Kim HN, Kim JB, Jeong SH. Remineralization effects when using different methods to apply fluoride varnish in vitro. J Dent Sci. 2018 Dec;13(4):360-6. https://doi.org/10.1016/i.jds.2018.07.004

30. Krüger CR. Dentin hypersensitivity - Mechanisms, permeability and desensitization techniques. J. Bras. Clin. Odontol. Integr. 2001;5:49-54.

31. Lopes RM, Turbino ML, Zezell DM, Scaramucci T, Aranha AC. The effect of desensitizing dentifrices on dentin wear and tubule occlusion. Am J Dent. 2015 Oct;28(5):297-302.

32. Klukowska M, Grender JM, Conde E, Goyal CR. A 12-week clinical comparison of an oscillating-rotating power brush versus a marketed sonic brush with self-adjusting technology in reducing plaque and gingivitis. J Clin Dent. 2013;24(2):55-61.

33. Bizhang M, Schmidt I, Chun YP, Arnold WH, Zimmer S. Toothbrush abrasivity in a long-term simulation on human dentin depends on brushing mode and bristle arrangement PLoS One.2017; 21;12(2): e0172060. https://doi.org/10.1371/journal.pone.0172060

34. Lippert F, Arrageg MA, Eckert GJ, Hara AT. Interaction between toothpaste abrasivity and toothbrush filament stiffness on the development of erosive/abrasive lesions in vitro. Int Dent J. 2017 Dec;67(6):344-50. https://doi.org/10.1111/idj.12305

35. Turssi CP, Binsaleh F, Lippert F, Bottino MC, Eckert GJ, Moser EA, et al. Interplay between toothbrush stiffness and dentifrice abrasivity on the development of non-carious cervical lesions. Clin Oral Investig. 2019 Sep;23(9):3551-6. https://doi.org/10.1007/s00784-018-2776-4

36. Huysmans MC, Young A, Ganss C. The role of fluoride in erosion therapy. Monogr Oral Sci. 2014;25:230-43. https://doi.org/10.1159/000360555 
Influence of Er,Cr:YSGG laser on root dentin submitted to erosive and/or abrasive challenges

37. Lussi A, Carvalho TS. The future of fluorides and other protective agents in erosion prevention. Caries Res. 2015;49 Suppl 1:18-29. https://doi.org/10.1159/000380886

38. Geraldo-Martins VR, Lepri CP, Palma-Dibb RG. Influence of Er,Cr:YSGG laser irradiation on enamel caries prevention. Lasers Med Sci. 2013 Jan;28(1):33-9. https://doi.org/10.1007/s10103-012-1056-9

39. Hossain M, Kimura Y, Nakamura Y, Yamada Y, Kinoshita Jl, Matsumoto K. A study on acquired acid resistance of enamel and dentin irradiated by Er,Cr:YSGG laser. J Clin Laser Med Surg. 2001 Jun;19(3):159-63. https://doi.org/10.1089/10445470152927991

40. Pourshahidi S, Ebrahimi H, Mansourian A, Mousavi Y, Kharazifard M. Comparison of Er, Cr:YSGG and diode laser effects on dentin hypersensitivity: a split-mouth randomized clinical trial. Clin Oral Investig 2019 Nov;23(11):4051-8. https://doi.org/10.1007/s00784-019-02841-z 